\title{
Surgical-site infection in spinal injury: incidence and risk factors in a prospective cohort of 518 patients
}

\author{
Arnaud Dubory $\cdot$ Hadrien Giorgi $\cdot$ Axel Walter $\cdot$ Benjamin Bouyer $\cdot$ \\ Matthieu Vassal - Fahed Zairi - Alexandre Dhenin · Michael Grelat • \\ Nicolas Lonjon · Cyril Dauzac · Guillaume Lonjon
}

Received: 6 January 2014/Revised: 17 August 2014/ Accepted: 18 August 2014/Published online: 23 August 2014

(c) Springer-Verlag Berlin Heidelberg 2014

\begin{abstract}
Purpose To investigate the incidence of surgical-site infection (SSI) and determinate the risk factors of SSI in the context of spinal injury.

Methods From February 1, 2011 to July 31, 2011, for a multicentre cohort of patients with acute spinal injury, we prospectively censored those with SSI for at least 12 months. We recorded epidemiologic characteristics and details of surgical procedure and postoperative care for each patient. We calculated the incidence of SSI at 1, 3 and 12 months after surgery. Univariate and multivariate analysis were used to establish the association of risk factors
\end{abstract}

\section{A. Dubory ( $\square)$}

Tumor and Spine Unit, Orthopaedic Department, Bicêtre University Hospital, AP-HP Paris, 78 Rue du Général Leclerc, 94270 Le Kremlin-Bicêtre, France

e-mail: arnauddubory@ hotmail.fr

A. Dubory

JE 2494, Univ Paris-Sud Orsay, 01405 Orsay, France

H. Giorgi

Spine Unit, Department of Orthopaedic Surgery, La Conception Hospital, AP-HM Marseille, Aix-Marseille University, 147

Boulevard Baille, 13005 Marseille, France

e-mail: hadriengiorgi@gmail.com

\section{A. Walter}

Service de Chirurgie du Rachis Pavillon Chirurgical B- Hôpitaux universitaires de Strasbourg, B.P.426-67091, Strasbourg Cedex, France

e-mail: axel.walter@chru-strasbourg.fr

B. Bouyer

Department of Orthopaedic and Sport Traumatology Surgery, AP-HP Paris, Hôpital Pitié-Salpêtrière, 47-83, Boulevard de L'hôpital, 75013 Paris, France

e-mail: benjamin.bouyer@u-psud.fr and SSI. We studied clinical outcomes by a visual analog scale for pain and physical and mental component summaries (PCS and MCS) of the Medical Outcomes Survey 36-Item Short Form (SF-36).

Results At 1 year, among 518 patients, we recorded 25 SSI events, with median occurrence at 16 days (25-75\% quartile: 13-44 days). Incidence of SSI was 3.2\% (95\% confidence interval [1.9-5.3\%]) at 1 month, $3.7 \%(95 \%$ [2.2-5.8\%]) at 3 months and $4.6 \%(95 \%$ CI [3-6.9\%]) at 12 months. On multivariate analysis, age, presence of diabetes and surgical duration were predictors of SSI ( $p=0.009, p=0.047$, and $p=0.015$ respectively). At 12 months, infected and non-infected patients did not differ

M. Vassal · N. Lonjon

Department of Neurosurgery, Gui de Chauliac Hospital, 80,

Avenue Augustin Fliche, 34090 Montpellier, France

e-mail: vassalmatthieu@gmail.com

N. Lonjon

e-mail: nlonjon@gmail.com

M. Vassal · N. Lonjon

INSERM U1051, Saint Eloi Hospital, Institute for Neurosciences of Montpellier, 34090 Montpellier, France

F. Zairi

Department of Neurosurgery, Lille University Hospital, Roger

Salengro Hospital, Rue Emile Laine, 59037 Lille, France

e-mail: fahed.zairi@gmail.com

\section{A. Dhenin}

Spine Unit, Department of Orthopaedic Surgery, University

Hospital of Bordeaux, Place Amélie Raba-Léon,

33000 Bordeaux, France

e-mail: adhenin13@gmail.com

A. Dhenin

Victor Ségalen University, Bordeaux 2, France 
in pain $(p=0.58)$ or SF-36 PCS $(p=0.8)$ or MCS $(p=0.68)$.

Conclusions In this large prospective multicentre study in the context of spinal injury, we obtained an equivalent incidence rate and risk factors of SSI as found in the literature for elective spinal surgery.

Keywords Surgical-site infection - Spinal injury · Incidence rate $\cdot$ Risk factor · Prospective study

$\begin{array}{ll}\text { Abbreviations } \\ \text { ASA } & \text { American Society of Anaesthesiology } \\ \text { ASIA } & \text { American Spinal Injury Association } \\ \text { BMI } & \text { Body mass index } \\ \text { MCS } & \text { Mental composite summary } \\ \text { NNIS } & \text { National Nosocomial Infection Surveillance } \\ \text { PCS } & \text { Physical composite summary } \\ \text { SF-36 } & \text { 36-Item Medical Outcomes Survey Short Form } \\ \text { SA } & \text { Staphylococcus aureus } \\ \text { SSI } & \text { Surgical-site infection }\end{array}$

\section{Introduction}

Spinal injury remains a real public health problem [1]. In fact, spinal injury is a frequent abnormality, concerning a young population, with non-negligible economic cost [2]. Because of the development of spinal instrumentation, the surgical alternative has become the procedure of choice for spinal fracture. In elective spinal surgery, the incidence of surgical-site infection (SSI) is $0.5-10 \%$ depending on the clinical study [3, 4]. Furthermore, SSI is a dreaded postoperative complication because it increases the length of hospitalization and leads to surgical debridement and prolonged need for intravenous antibiotic therapy $[5,6]$.

\footnotetext{
M. Grelat

Department of Neurosurgery, University Hospital of Dijon, Medicine University of Dijon, 7 rue isabelle de portugal, 21000 Dijon, France

e-mail: michael.grelat@gmail.com

C. Dauzac

Department of Orthopaedic Surgery, Beaujon Hospital, AP-HP Paris, Paris Diderot University, 100 Boulevard General Leclerc, 92110 Clichy, France

e-mail: cyril.dauzac@gmail.com

\section{G. Lonjon}

Orthopaedic Surgery Department, Raymond Poincaré Hospital, AP-HP Paris, Versailles Saint-Quentin University, 104, Boulevard Raymond Poincaré, 92380 Garches, France e-mail: guilonjon@gmail.com
}

Spinal injury seems to increase the risk of postoperative SSI [3, 7]. Patients with spinal injury generally experience multiple traumas potentially involving hemodynamic, neurologic or respiratory dysfunction, which facilitates the occurrence of SSI [8]. Nevertheless, few studies have investigated SSI after traumatic spinal injury. Blam et al. [3], in a retrospective review of 1,561 patients, revealed an infection rate of $9.4 \%$. Rechtine et al. [7], in a case series of 117 patients with thoracic and lumbar fracture, reported a $10 \%$ rate of SSI. A pilot study of 169 selective patients undergoing surgery for spinal trauma revealed an early incidence rate (3 months) of $3.7 \%$ [9].

In the present study, we assessed the incidence and risk factors of SSI related to surgery for spinal injury in an important multicentre prospective cohort with a minimum follow-up of 12 months.

\section{Materials and methods}

\section{Patients}

We included data for patients with recent spinal injury ( $<3$ months) requiring surgery (from C1 to L5 vertebrae) in 10 spine surgery centers in France between February 1, 2011 and July 31, 2011. All centers are specialized in elective and trauma spinal surgery. Spinal injury was considered spinal fracture, spinal dislocation or serious cervical sprain. Patients with non-traumatic spinal fracture and tumoral spinal abnormalities were excluded. Patients were followed at 1, 3 and at least 12 months after the procedure. We followed guidelines for reporting observational studies according to the Strengthening the Reporting of Observational Studies in Epidemiology (STROBE) statement [10] (Appendix 1).

Diagnosis of superficial and deep SSI

The occurrence of SSI was recorded. The definition of SSI was from the US Centers for Disease Control and Prevention [11, 12]. We defined superficial SSI as involving only the skin or subcutaneous tissue of the incision and not extending into the facial and muscle layers and at least one of the following:

1. Purulent drainage, with or without laboratory confirmation, from the superficial incision.

2. Organisms isolated from an aseptically obtained culture of fluid or tissue from the superficial incision.

3. At least one of the following signs or symptoms of infection: pain or tenderness, localized swelling, redness, or heat and superficial incision is deliberately opened by the surgeon, unless the site is culturenegative. 
Table 1 Potential risk factors of surgical-site infection (SSI) with spinal injury

\begin{tabular}{lll}
\hline Epidemiologic characteristics (15) & Surgical procedure (10) & Postoperative care (4) \\
\hline Age & Preoperative skin antiseptic & Length of intensive car unit stay \\
Sex & Antibioprophylaxis & Postoperative wound drain \\
Comorbidities & Surgical duration $(\leq$ or $>3 \mathrm{~h})$ & Urinary catheter \\
Body mass index & Conventional or minimally & Surgical complications (hematoma, postoperative \\
& invasive surgery & neurologic impairment, instrument failure) \\
American Society of anaesthesiology score & No. of instrumented vertebrae & \\
Diabetes & Delay of spinal surgery & \\
Smoking & Intraoperative blood loss & \\
Neurologic deficit (ASIA score) & Neurologic decompression & \\
Complete neurologic deficit & Intraoperative dural tear & \\
Bladder and bowel dysfunction & Intraoperative blood transfusion & \\
Polytrauma (open fracture, thoracic or & & \\
abdominal trauma, soft tissue laceration) & & \\
Etiology of spinal fracture & & \\
Level of spinal injury & & \\
Multi-level spinal injury & & \\
Timing of surgery following admission & \\
\hline
\end{tabular}

4. Diagnosis of superficial incisional SSI by the surgeon or attending physician.

Deep SSI involves deep soft tissues (e.g., fascial and muscle layers) of the incision and at least one of the following:

1. Purulent drainage from the deep incision but not from the organ/space component of the surgical site.

2. A deep incision spontaneously dehisces or is deliberately opened by a surgeon when the patient has at least one of the following signs or symptoms: fever $\left(>38{ }^{\circ} \mathrm{C}\right)$, localized pain, or tenderness, unless the site is culture-negative.

3. An abscess or other evidence of infection involving the deep incision is found on direct examination, during reoperation, or by histopathologic or radiologic examination.

4. Diagnosis of a deep incisional SSI by a surgeon or attending physician.

SSI that involved both superficial and deep incision sites was considered deep incisional SSI.

\section{Risk factors of SSI and evaluation of clinical outcome}

We sought potential risk factors of SSI related to epidemiologic characteristics, surgical procedure and postoperative care (Table 1). Also, for each case, we calculated the National Nosocomial Infection Surveillance (NNIS) Index, which evaluates the risk of SSI according to American Society of Anaesthesiologists (ASA) classification of physical health; the Altemeier wound contamination class and surgical duration. Spinal surgery is class 1 ("clean surgery") in the Altemeier classification. Each factor is rated 0 or 1 in terms of presence or absence, respectively, of the risk factor.

Death and its aetiology were recorded. Clinical outcome was collected at 12 months in terms of a visual analog scale (VAS) for pain and the Medical Outcomes Survey 36-item Short Form (SF-36) with physical and mental component summaries (PCS and MCS).

\section{Clinical and biological features of SSI}

Usually, practitioners consider acute SSI as occurring up to 3 months after surgery. In fact, if SSI develops during this period, surgical debridement is indicated, whereas delayed infections require a change in instrumentation associated with debridement [13-15]. Delay of SSI occurrence, temperature, signs of meningitis, and local characteristics were recorded. Leucocytes were counted and C-reactive protein level was measured. Type of treatment was recorded (surgery or conservative treatment). The number of iterative surgeries was specified. For bacteriological diagnosis, the type of bacterium, culture antibiogram, and positive blood cultures were analyzed. For surgical procedure, we studied implant failure, changes in material, and retained graft. The type and number of antibiotics, duration of intravenous treatment and probabilistic antibiotic treatment, and complications related to antibiotics were recorded. Radiographic assessment was performed to search for local mechanical failure. 
Statistical analysis

\section{Incidence of SSI}

Continuous data are described with mean \pm SD or median (25-75\% quartile). Categorical data are described with number (percentage). The incidence of SSI was evaluated at 1, 3 and 12 months after the first spine surgery. For the principal analysis, we considered the gross incidence. For sensitivity analysis, we calculated the incidence rate by survival using the Kaplan-Meier method. We defined SSIfree survival as the time from surgery to the occurrence of SSI. We defined the starting point as the first surgery and the endpoint as the occurrence of SSI or the last follow-up. Data were censured for patients who were lost to follow-up or died. We defined cumulative survival as the time from the surgery to the occurrence of death. We defined the starting point as the first surgery and the endpoint as the occurrence of death. Data were censured for patients who were lost to follow-up.

\section{Risk factors of SSI}

Univariate analysis was used to assess the association of potential risk factors and SSI. Student's $t$ test or MannWhitney-Wilcoxon test was used for continuous variables and Chi-square test or Fisher exact test for categorical variables. Multivariate analysis was used to identify independent risk factors of SSI. All variables associated with SSI on univariate analysis $(p<0.2)$ were included in the logistic multiple regression analysis. The selection of variables involved a stepwise method with a backward direction. The final model was checked for goodness of fit with the Hosmer-Lemeshow test. As well, the discrimination of the final model was evaluated. Comparison of clinical outcomes (VAS score and SF-36) involved the non-parametric Fisher test. $p<0.05$ was considered statistically significant. Statistical analyses involved use of $\mathrm{R}$ v10.13 (R Development Core Team [2011]).

\section{Results}

Characteristics of the study sample (Tables 2, 3)

The multicentre cohort of 518 patients included 354 males $(68.3 \%)$. The mean age was $47.8 \pm 19.1$ years and BMI $24.8 \pm 4.5 \mathrm{~kg} / \mathrm{m}^{2}$. In total, $88 \%$ of patients had an ASA comorbidity score of 1 or 2 . The origin of spinal injury was road traffic injury for 184 patients $(35 \%)$, defenestration for $30(6 \%)$, domestic accident for $113(22 \%)$, falls for $132(25 \%)$, sport for $37(7 \%)$, and other etiologies for 22 $(5 \%)$. The site of spinal injury was mainly thoracolumbar
(41\%), lower cervical spine (27\%), thoracic spine (14\%), lumbar spine $(11 \%)$ and upper cervical spine (7\%). Polytrauma was present for 157 patients (30\%), among them 37 had open limb fractures, 32 had soft tissue laceration, 85 had thoracic trauma, 17 abdominal trauma and 51 had traumatic brain injury. In total, 155 patients (30\%) had more than one spinal fracture, and 145 (28\%) presented neurologic dysfunctions at the first clinical examination (ASIA score A to D).

\section{Surgical procedure (Tables 2, 3)}

The median surgical delay was 3 days $(25-75 \%$ quartile 1-6 days) after spinal trauma for patients without neurologic deficit and 1 day (0-2 days) for patients with neurologic deficit. Surgery for 322 patients $(97 \%)$ with thoracic, lumbar and thoracolumbar fractures was performed initially by the posterior approach; for $110(83 \%)$ with lower cervical-spine fractures, it was performed by the anterior approach. Whatever the level of injury, surgery was anterior for 137 patients $(28 \%)$ and posterior for 381 $(72 \%)$. All patients received preoperative antibioprophylaxia (cefazolin $2 \mathrm{~g}$ ). In case of surgery longer than $4 \mathrm{~h}$, patients received a second dose of antibiotic. In case of allergy, cefazolin was substituted by a single dose of clindamycin. For most patients (92\%), the surgery duration was $\leq 3 \mathrm{~h}$. The mean preoperative blood loss was $356 \pm 400 \mathrm{ml}$. The mean number of instrumented vertebrae was $4( \pm 2)$. In all, 99 patients $(28 \%)$ underwent minimally invasive surgery, with mean blood loss of $60 \mathrm{ml}$.

\section{Postoperative care}

Due to some clinical features (polytrauma, comorbidities and neurologic deficits), 131 patients were hospitalized in intensive care unit. Median of length of stay in an intensive care unit was 8 days (25-75\% quartile 4-20 days). The intensive care unit stay was necessary for 85 patients 10 days (25-75\% quartile $4-22$ days) with and 45 patients 8 days (25-75\% quartile 4-12 days) without neurologic injury. No patients received corticosteroids in postoperative care. Non-septic complications such as implant failure, pseudarthrodesis, and hematoma were recorded in 16 cases $(3 \%)$. Five patients died during hospitalization $(0.01 \%)$. A brace was recommended for 259 patients $(50 \%)$. The median hospital duration was 18 days (25-75\% quartile 9-28 days) with and 7 days (5-11 days) without neurologic injury, respectively.

At 1,3 and 12 months, we clinically assessed 478 $(92.2 \%), 476(91.8 \%)$ and 372 patients (72\%), respectively. 
Table 2 Clinical and biological features of spinal-injury patients with SSI ( $n=518 / 10$ spine trauma units)

\begin{tabular}{|c|c|}
\hline \multicolumn{2}{|l|}{ Characteristics } \\
\hline \multicolumn{2}{|l|}{ Sex } \\
\hline Male & $354(68.3 \%)$ \\
\hline Female & $164(31.7 \%)$ \\
\hline Sex ratio & 2.2 \\
\hline Age (year) & $47.8 \pm 19.1$ \\
\hline Body mass index $\left(\mathrm{kg} / \mathrm{m}^{2}\right)$ & $24.8 \pm 4.5$ \\
\hline \multicolumn{2}{|c|}{$\begin{array}{l}\text { American Society of Anaesthesiologists (ASA) classification of } \\
\text { physical health }\end{array}$} \\
\hline 1 & $286(58 \%)$ \\
\hline 2 & $171(32 \%)$ \\
\hline 3 & $57(11 \%)$ \\
\hline 4 & $4(1)$ \\
\hline 5 & 0 \\
\hline 6 & 0 \\
\hline \multicolumn{2}{|l|}{ Etiology of spinal trauma } \\
\hline Road traffic injury & $184(35 \%)$ \\
\hline $\begin{array}{l}\text { Defenestration accident (suicide } \\
\text { attempt) }\end{array}$ & $30(6 \%)$ \\
\hline Domestic accident & $113(22 \%)$ \\
\hline Falls & $132(25 \%)$ \\
\hline Sport & $37(7 \%)$ \\
\hline Other & $22(5 \%)$ \\
\hline Occupational injury & $53(10 \%)$ \\
\hline Polytrauma & $157(30 \%)$ \\
\hline \multicolumn{2}{|l|}{ Level of spinal injury } \\
\hline Upper cervical spine (C1-C2) & $37(7 \%)$ \\
\hline Lower cervical spine (C3-C7) & $133(27 \%)$ \\
\hline Thoracic spine (T1-T11) & $71(14 \%)$ \\
\hline Thoracolumbar spine (T12-L1) & $202(41 \%)$ \\
\hline Lumbar spine (L2-L5) & $53(11 \%)$ \\
\hline \multicolumn{2}{|l|}{ Neurological status (ASIA score) } \\
\hline \multicolumn{2}{|l|}{ Unknown $=25$} \\
\hline A & $50(10 \%)$ \\
\hline $\mathrm{B}$ & $25(5 \%)$ \\
\hline $\mathrm{C}$ & $24(5 \%)$ \\
\hline $\mathrm{D}$ & $39(8 \%)$ \\
\hline $\mathrm{E}$ & $358(72 \%)$ \\
\hline \multicolumn{2}{|l|}{ Multi-level spinal injury $(n=22)$} \\
\hline $\begin{array}{l}\text { Upper cervical spine }+ \text { lower cervical } \\
\text { spine }\end{array}$ & $3(14 \%)$ \\
\hline Lower cervical spine + thoracic spine & $1(5 \%)$ \\
\hline Thoracic spine + lumbar spine & $4(20 \%)$ \\
\hline Thoracolumbar spine + lumbar spine & $14(61 \%)$ \\
\hline \multicolumn{2}{|l|}{ No. of vertebral fractures } \\
\hline 1 & $370(71 \%)$ \\
\hline 2 & $107(20 \%)$ \\
\hline 3 & $23(5 \%)$ \\
\hline$>3$ & $18(4 \%)$ \\
\hline
\end{tabular}

Table 2 continued

\begin{tabular}{ll}
\hline Characteristics & \\
\hline Surgical approach & $137(28 \%)$ \\
Anterior & $381(72 \%)$ \\
Posterior & 0 \\
Combined & \\
No. of instrumented vertebrae & $96(20 \%)$ \\
2 & $156(33 \%)$ \\
3 & $61(13 \%)$ \\
4 & $92(19 \%)$ \\
5 & $43(9 \%)$ \\
6 & $36(7 \%)$ \\
$>6$ & $99(20 \%)$ \\
Minimally invasive surgery & $481(92 \%)$ \\
Operative duration & $37(8 \%)$ \\
$\leq 3$ h & $356 \pm 400$ \\
$>3$ h & $4-12)$ \\
Peroperative blood loss (ml) & \\
Timing of surgery following admission (day) \\
Absence of neurologic deficit & $3(25-75 \%$ quartile 1-6) \\
Presence of neurologic deficit & $1(25-75 \%$ quartile 0-2) \\
Length of postoperative intensive care unit stay \\
Presence of neurologic deficit \\
Absence of neurologic deficit & $10(25-75 \%$ quartile \\
& $4-22)$ \\
& \\
&
\end{tabular}

Incidence of SSI (Fig. 1; Table 2)

At 1 month, 3 patients died not due to the presence of local infection during hospitalization and 35 patients were lost to follow-up. In all, 16 patients showed SSI, with 2 dying in a context of polytrauma. The gross incidence rate at 1 month was $3.1 \%$ (95\% CI [1.8-5.0\%]). Survival-free SSI was $96.6 \%$ (95\% CI [94.8-98.2\%]).

At 3 months, 2 more patients died, and the number of cases of SSI increased by 6 ( $22 \mathrm{SSI})$, with a gross incidence rate of $4.2 \%$ (95 \% CI [2.7-6.4\%]). Survival-free SSI was $95.3 \%$ (95\% CI [93.31-97.2\%]).

At 12 months, 2 more patients died, and the number of cases of SSI increased by 3 ( $25 \mathrm{SSI})$, with a gross incidence rate of $4.8 \%$ (95 \% CI [3.2-7.4\%]). Survival-free SSI was $94.5 \%$ (95\% CI [92.4-96.6\%]). At 12 months, we censored at least 25 cases of SSI. Cumulative survival analysis is in Fig. 2. The incidence rate in worst-case scenario (each patient lost to follow-up was considered as infected) was $33 \%$ (95\% CI [29-37.4\%]).

The incidence of SSI at 12 months was $8.1 \%(95 \% \mathrm{CI}$ [2.1-23\%]) (3 SSI/37 fractures) with injury at the upper cervical spine, $0 \%$ (95\% CI [0-3.4\%]) (0 SSI/133 fractures) at the lower cervical spine, $8.4 \% \quad(95 \%$ CI 
Table 3 Surgical characteristics by spinal area injured

\begin{tabular}{|c|c|c|c|c|c|}
\hline & $\begin{array}{l}\text { Upper cervical spine } \\
(\mathrm{C} 1-\mathrm{C} 2)(n=37)\end{array}$ & $\begin{array}{l}\text { Lower cervical spine } \\
(\text { C3-C7) }(n=133)\end{array}$ & $\begin{array}{l}\text { Thoracic spine } \\
(\mathrm{T} 1-\mathrm{T} 11)(n=71)\end{array}$ & $\begin{array}{l}\text { Thoraclumbar spine } \\
(\mathrm{T} 12-\mathrm{L} 2)(n=202)\end{array}$ & $\begin{array}{l}\text { Lumbar spine } \\
\text { (L3-L5) }(n=54)\end{array}$ \\
\hline \multicolumn{6}{|l|}{ Surgical approach } \\
\hline Anterior (\%) & $19(51 \%)$ & $111(83 \%)$ & $1(1 \%)$ & $3(2 \%)$ & $2(4 \%)$ \\
\hline Posterior (\%) & $18(49 \%)$ & $22(17 \%)$ & $70(99 \%)$ & $198(98 \%)$ & $52(96 \%)$ \\
\hline \multicolumn{6}{|l|}{ Operative duration } \\
\hline$\leq 3 \mathrm{~h}$ & $34(92 \%)$ & $126(95 \%)$ & $64(90 \%)$ & $189(93 \%)$ & $52(96 \%)$ \\
\hline $3 \mathrm{~h}$ & $3(8 \%)$ & $7(5 \%)$ & $7(10 \%)$ & $13(7 \%)$ & $1(4 \%)$ \\
\hline \multicolumn{6}{|c|}{ Intraoperative blood loss (ml) } \\
\hline Median (Q1-Q3) & $150(50-300)$ & $150(50-300)$ & $500(300-800)$ & $200(80-500)$ & $200(50-500)$ \\
\hline SSI & $(3 / 37)$ & $(0 / 133)$ & $(6 / 71)$ & $(11 / 202)$ & $(2 / 54)$ \\
\hline Superficial & 0 & 0 & 1 & 1 & 1 \\
\hline Deep & 3 & 0 & 5 & 10 & 1 \\
\hline
\end{tabular}

Data are mean \pm SD or no. $(\%)$

[3.4-18.1\%]) (6 SSI/71 fractures) at the thoracic spine, $5.4 \%$ (95\% CI [2.8-9.7\%]) (11 SSI/202 fractures) at the thoracolumbar spine and $3.7 \%$ (95\% CI [0.6-14\%]) (2 $\mathrm{SSI} / 53$ fractures) at the lumbar spine.

\section{Clinical and biological features of SSI}

The median occurrence of SSI was 16 days (25-75\% quartile 13-44 days; range 7-122 days). The median hospitalization was 28 days $(25-75 \%$ quartile 18-35 days) for infected patients and 8 days $(25-75 \%$ quartile 5-12 days) for non-infected patients $(p<0.05)$. The clinical features were fever $\left(>38^{\circ} \mathrm{C}\right)$ for 11 patients [45.8\%; median $38.8{ }^{\circ} \mathrm{C} \quad(25-75 \%$ quartile 38.2$\left.39.5^{\circ} \mathrm{C}\right)$ ] and inflammatory wounds for $22(91.7 \%)$. We noted no signs of meningitis. The mean C-reactive protein level was $160 \mathrm{mg} / \mathrm{l}$ (25-75\% quartile 60-320 mg/l) and median number of leukocytes 13,300 (11,200-18,700). Three were superficial SSI and 22 were deep. In total, 21 patients needed surgical debridement, irrigation and wound cleaning. One case needed a change of instrumentation. The autograft bone was preserved in 15 cases. Three patients underwent iterative surgeries of debridement to treat SSI.

A bacterium was found in all 25 cases of SSI censored; 18 were considered commensal bacteria. Double or triple antibiotic treatment for meticillin-resistant Staphylococcus aureus (SA) infection was prescribed in 12 cases (50\%). More than 2 kinds of bacteria were discovered in 6 cases (25\%). Two patients $(8.3 \%)$ had meticillin-resistant SA infection, $2(8.3 \%)$ coagulase-negative SA infection and 5 (20.8\%) Escherichia coli infection. The duration of antibiotic treatment was 90 days for 14 patients $(58.3 \%)$, 45 days for $4(16.7 \%)$ and 21 days for $6(25 \%)$.
At last follow-up, among 25 patients with local infection, infection was considered healed for $21(87.5 \%)$. One patient was lost to follow-up. Two patients died because of SSI. In one male patient 74 years old with multiple comorbidities (diabetes, renal failure) who underwent surgery for spinal thoracic fracture (Magerl B) after a car accident, with ASIA A score, SSI complicated by general infection developed after 7 days. In one female patient 92 years old who underwent surgery for odontoid fracture had posterior C1-C2 arthrodesis. She was receiving antiagregant treatment and had massive intraoperative blood loss $(2500 \mathrm{cc})$. She was intubated during postoperative care and had ventilator-associated pneumonia complicated by SSI and septic shock. One patient was still under observation for clinical features suggesting bone non-union.

\section{Risk factors of SSI}

Age, BMI, number of operated vertebrae and intraoperative blood loss were associated with SSI on univariate analysis (all $p<0.05$ ). As well, the presence of diabetes, surgical duration $>3 \mathrm{~h}$, posterior surgical approach, neurologic decompression, intraoperative blood transfusion, presence of bladder catheter and elevated NNIS score were associated with SSI (all $p<0.05$ ). On multivariate analysis, only age, presence of diabetes and surgical duration $>3 \mathrm{~h}$ were predictors of SSI (all $p<0.05$ ) (Table 4).

\section{Clinical and functional outcomes}

At 12 months, we had VAS pain and SF-36 data for 340 patients, 17 with SSI. Patients with and without infection did not differ in VAS pain $(p=0.58)$ or SF-36 PCS $(p=0.8)$ or $\operatorname{MCS}(p=0.68)$ (Fig. 3). 

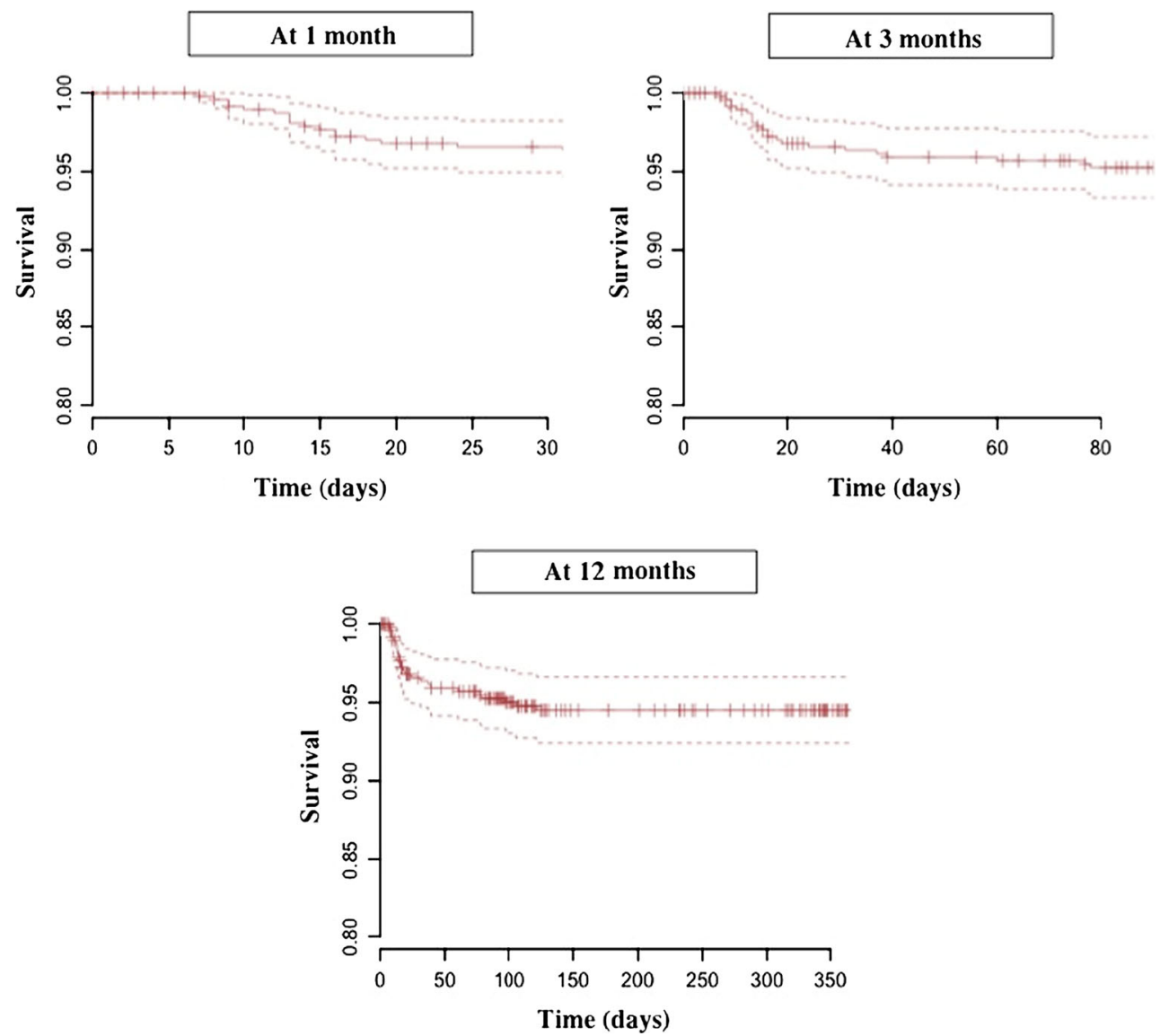

Fig. 1 Kaplan-Meier survival-free curves for 518 patients with surgical-site infection (SSI) at 1, 3 and 12 months after surgery

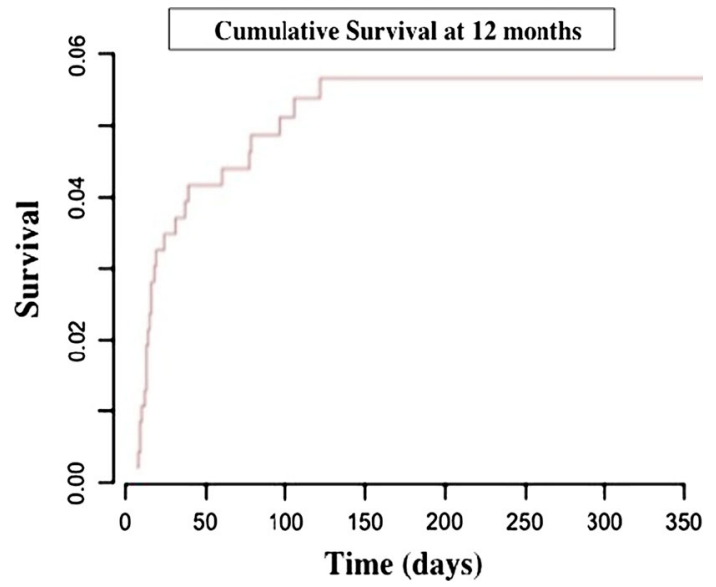

Fig. 2 Cumulative survival curve of surgical-site infection (SSI) for 25 patients infected at 12 months

\section{Discussion}

From a cohort of 518 patients, at 12 months after surgery for spinal injury, 25 showed SSI, for a gross incidence rate of $4.8 \%$ (95\% CI [3.2-7.4\%]); 16 had acute SSI $(<1-$ month duration). On multivariate analysis, age, presence of diabetes and surgical duration $>3 \mathrm{~h}$ were independent risk factors of SSI. These results are comparable with those in the literature $[3,5,7]$.

The Scoliosis Research Society (SRS) morbidity and mortality committee noted an overall infection rate of $2.0 \%$ after surgery for spinal fracture in 6,025 patients [4]. This result is the most favorable SSI rate in the field of spinal injury. Experienced surgeons, a retrospective analysis (poor internal validity) and lack of methods to determine the completeness of incidence could explain this rate. SRS members could be more experienced than the surgeons in our study. Even if not demonstrated, a wellexperienced surgeon could have decreased SSI rate and fewer perioperative complications. Studies of other specialities have highlighted the relationship between surgical experience and postoperative morbidity as SSI [16]. Furthermore, the impact of spinal injury on the occurrence of SSI has not been clearly demonstrated. Several authors suggested that spinal injury could be a risk factor of SSI [3, 7]. Nevertheless, all these studies were retrospective and only one compared the incidence of SSI for elective and spinal-injury surgery. In fact, Blam et al. [3], in a retrospective review of 256 patients with surgery for spinal 
Table 4 Multivariate regression model of factors predicting spinal SSI

\begin{tabular}{llr}
\hline & OR $(95 \% \mathrm{CI})$ & $p$ value \\
\hline Age $(>65$ years $)$ & $3.56(1.36-9.30)$ & 0.009 \\
Presence of diabetes & $3.42(1.01-11.57)$ & 0.047 \\
Surgical duration $(>3 \mathrm{~h})$ & $4.02(1.31-12.38)$ & 0.015 \\
\hline
\end{tabular}

Other covariates in the final model: surgical approach, peroperative blood loss and ureteral catheter. Hosmer-Lemeshow goodness-of-fit Chisquare, $p=0.18$. Discrimination test: area under the receiver operating characteristic curve $=0.84$

$95 \%$ CI $95 \%$ confidence interval

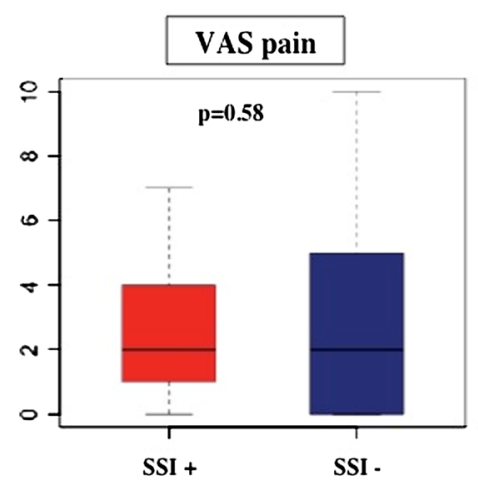

Fig. 3 Box plots of clinical and functional outcomes at 12 months by presence and absence of surgical-site infection (SSI): pain on a visual analog scale (VAS), Medical Outcomes Survey 36-item Short Form

injury, demonstrated a rate of SSI of $9.4 \%$. In the same period, the rate of SSI for 2,990 patients undergoing elective surgery was significantly lower, $3.7 \%$ $(p<0.001)$.

We highlighted 3 independent risk factors of SSI: age, presence of diabetes and surgical duration $>3 \mathrm{~h}$. These results are not surprising: surgery in older adults represents an at-risk procedure in terms of both the anesthetic and surgical plan [17-20]. Furthermore, this phenomenon is continually increased because of the aging of the population in industrialized countries. Carreon et al. [21], in studying postoperative complications of posterior lumbar decompression and arthrodesis in older adults, found that the most common major complication was SSI, with a prevalence of $10 \%$. Diabetes was previously found a risk factor of SSI, and its prevalence is continually increasing as well [22, 23]. In addition, numerous authors have found surgical duration a risk factor of SSI. Kim et al. [24], in a retrospective analysis of 4,588 surgical cases of singlelevel lumbar fusions, found an association of surgical duration $>5 \mathrm{~h}$ and occurrence of wound dehiscence and deep SSI. Veeravagu et al. [25], in a prospective study of 24,774 patients undergoing spinal decompression and fusion surgery, demonstrated surgical duration up to $3 \mathrm{~h}$ as a significant predictor of postoperative infection. We

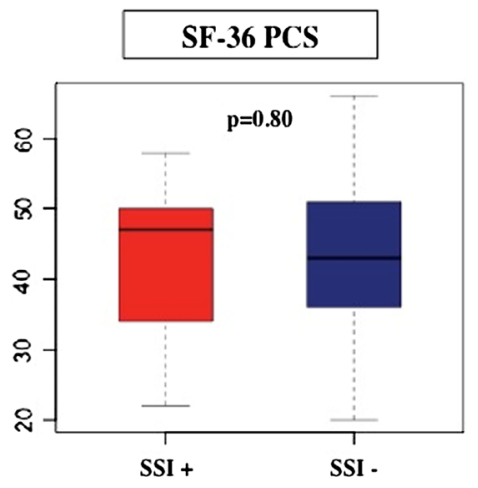

(SF-36) mental component summary (MCS) and physical component summary (PCS)

found that the surgical approach and number of operated vertebrae did not significantly influence SSI on multivariate analysis, but Xing et al. [26], in a systematic review of 36 observational studies involving 2,439 patients, noted obesity or BMI, long operation time, diabetes, smoking, history of previous SSI and type of surgical procedure associated with SSI. We did not assess the impact of steroids on occurrence of SSI. In France, most centers do not use steroids and forbid their use. In fact, NASCIS 1 and 2 trials [27] showed a limited advantage of methylprednisolone on neurologic recovery administered within $8 \mathrm{~h}$ after spinal-cord injury. Moreover, the NASCIS 3 trial [28] showed an increase of severe pneumonia $(p=0.02)$ with steroids but no significant difference in SSI. Even if SSI is a serious surgical complication, the abnormality is well-known and well-controlled by early surgical debridement and intravenous antibiotic treatment [15]. In fact, we found only two deaths directly related to SSI in the context of polytrauma, and injury had healed in all patients who had undergone surgical debridement and antibiotic treatment. Kuo et al. [29] found complete healing in 27 patients with 30 cases of spinal deep SSI after treatment including surgical debridement and antibiotics. Rarely is iterative surgery of debridement and reconstruction needed. The clinical outcomes of patients 
with spinal SSI seem to be less complicated than with other SSI. For example, SSI after hip or knee joint arthroplasty often needs iterative surgical revision until prosthesis replacement [30]. We found equivalent clinical and functional outcome among infected and non-infected patients, but several studies have found reduced long-term clinical recovery and long-term persistence of low back pain. Petilon et al. [31] demonstrated greater back pain in patients with acute and deep SSI after surgical lumbar spinal fusion than those without SSI. Furthermore, although clinical results were similar between infected and non-infected patients in comparing intra- and postoperative complications, we do not know the effect of acute SSI on spinal fusion and long-term implant failure. Assessing radiological outcome of infected patients and seeking a potential link between SSI and pseudoarthrodesis in a context of spinal fracture would be of interest [32].

The present study has some limitations. First, we may have underestimated the number of infected patients. Indeed, 146 patients (28\%) were lost to follow-up and could have been infected. The theoretical worst scenario for infection was $33 \%$. Moreover, the definition of SSI [12] is not completely clear, and multiple clinical features of SSI were found for difficulty in classification (e.g., limited isolated fever with wound collection but clean scar). However, we defined SSI according to the US Centers for Disease Control. Moreover, SSI can be delayed and the final follow-up at 12 months is probably insufficient. Infection with the anaerobic Propionibacterium acnes $(P$. acnes) bacterium can cause delayed SSI. Uçkay et al. [33] showed that the mean delay between spinal surgery and SSI onset with $P$. acnes infection was 34 months (range
0-156 months). Nevertheless, Pull Ter Gunne et al. [5] in a retrospective review over 9 years, censored 132 cases of SSI from 3,174 patients included and reported an occurrence of SSI at a mean of 28.7 days after the index procedure. This study, with a long follow-up, demonstrated that most of the SSI occurred during the first month. In addition, in the definition of SSI from the Guidelines for the Prevention of SSI 1999, SSI has to occur within 1 year with instrumentation or implantation [11]. In addition, the number of SSI cases is low as compared with the number of potential covariates. The logistic regression model could be saturated, thus leading to over-fitting. A larger cohort would be more adequate in a context of a low rate of events.

In conclusion, we prospectively assessed the incidence of SSI over a long period in patients with spinal injury managed by surgery. Despite a non-negligible number of patients lost to follow-up, our study gives a reliable and exhaustive picture of infection outcomes after surgery for spinal injury. More specific studies of the level of injury or kind of procedure would clearly establish risk factors for SSI and improve the management of spinal injury needing surgery for stabilization $[34,35]$.

Acknowledgment The authors are grateful to the SFCR (French Spine Surgery Society) and its participating members (R. Assaker, JP. Steib, C. Court, JM. Vital, P. Guerin, S. Fuentes, H. Pascal Mousellard, JY Lazennec, R.Zahi, B. Augereau) and the SOFCOT (The French Society of Orthopaedic and Trauma Surgery).

\section{Appendix 1}

See Table 5 .

Table 5 STROBE checklist

\begin{tabular}{|c|c|c|}
\hline Item & $\begin{array}{l}\text { Item } \\
\text { number }\end{array}$ & Recommendation \\
\hline Title and abstract & 1 & $\begin{array}{l}\text { (a) Study design: Multicenter prospective cohort study } \\
\text { (b) Provide in the abstract an informative and balanced summary of what was done and what was found } \\
\text { Abstract (Page } 2 \text { Line 16): "In this large prospective multicentre study in the context of spinal injury, we obtained an } \\
\text { equivalent incidence rate and risk factors of SSI as found in the literature for elective spinal surgery" }\end{array}$ \\
\hline \multicolumn{3}{|l|}{ Introduction } \\
\hline $\begin{array}{l}\text { Background/ } \\
\text { rationale }\end{array}$ & 2 & $\begin{array}{l}\text { Explain the scientific background and rationale for the investigation being reported } \\
\text { Introduction (Page } 4 \text { Line 10): "Nevertheless, few studies have investigated SSI after traumatic spinal injury (...) an early } \\
\text { incidence rate ( } 3 \text { months) of } 3.7 \% \text { [9]" }\end{array}$ \\
\hline Objectives & 3 & $\begin{array}{l}\text { State specific objectives, including any pre-specified hypothesis } \\
\text { Introduction (Page } 9 \text { Line 15): "In the present study, we assessed the incidence and risk factors of SSI related to surgery for } \\
\text { spinal injury in an important multicentre prospective cohort with a minimum follow-up of } 12 \text { months" }\end{array}$ \\
\hline \multicolumn{3}{|l|}{ Methods } \\
\hline Study design & 4 & $\begin{array}{l}\text { Present key elements of study design early in the paper } \\
\text { Introduction (Page } 4 \text { Line 16): "in an important multicentre prospective cohort with a minimum follow-up of } 12 \text { months" }\end{array}$ \\
\hline Setting & 5 & $\begin{array}{l}\text { Describe the setting, locations and relevant dates, including periods of recruitment, exposure, follow-up and data collection } \\
\text { Methods (Page } 4 \text { Line 19): "We included data for patients with recent spinal injury ( }<3 \text { months) requiring surgery (from C1 to } \\
\text { L5 vertebrae) in } 10 \text { spine surgery centers in France between February } 1,2011 \text { and July } 31,2011 \text { " } \\
\text { Methods (Page } 4 \text { Line 22): "Patients with non-traumatic spinal fracture and tumoral spinal abnormalities were excluded" }\end{array}$ \\
\hline
\end{tabular}


Table 5 continued

\begin{tabular}{|c|c|c|}
\hline Item & $\begin{array}{l}\text { Item } \\
\text { number }\end{array}$ & Recommendation \\
\hline Participants & 6 & $\begin{array}{l}\text { (a) Cohort study-give the eligibility criteria, and the sources and methods of selection of participants. Describe methods of } \\
\text { follow-up } \\
\text { Eligibility criteria: } \\
\text { 1. Recent spinal injury ( }<3 \text { months) } \\
\text { 2. Requiring injury (from C1 to L5) } \\
\text { 3. Between February } 1,2011 \text { and July } 31,2011 \\
\text { Sources: STROBE guidelines } \\
\text { Methods of follow-up: follow-up at } 1 \text { month, } 3 \text { and } 12 \text { months }\end{array}$ \\
\hline Variables & 7 & $\begin{array}{l}\text { Clearly define all outcomes, exposures, predictors, potential confounders and effect modifiers. Give diagnostic criteria, if } \\
\text { applicable } \\
\text { Definition of deep and superficial SSI (diagnosis criteria): US Centers for Disease Control and Prevention } \\
\text { Potential risks factor of SSI: Table } 1 \\
\text { Clinical and biological features of SSI: Delay of SSI occurrence, temperature, signs of meningitis, local characteristics, } \\
\text { leucocytes, C-reactive protein level, type of treatment (surgery or conservative treatment), the number of iterative surgeries, } \\
\text { the type of bacterium, culture antibiogram, and positive blood cultures, implant failure, changes in material, and retained } \\
\text { graft, type and number of antibiotics, duration of intravenous treatment, probabilistic antibiotic treatment, Radiographic } \\
\text { assessment (local mechanical failure) } \\
\text { Clinical outcomes: Methods (Page } 6 \text { Line 1): "clinical outcome was collected at } 12 \text { months in terms of a visual analog scale } \\
\text { (VAS) for pain and the Medical Outcomes Survey 36-item Short Form (SF-36) with physical and mental component } \\
\text { summaries (PCS and MCS)" }\end{array}$ \\
\hline $\begin{array}{l}\text { Data sources/ } \\
\text { measurement }\end{array}$ & 8 & $\begin{array}{l}\text { Continuous data are described with mean } \pm \text { SD or median }(25-75 \% \text { quartile). Categorical data are described with number } \\
\text { (percentage). The incidence of SSI was evaluated at } 1,3 \text { and } 12 \text { months after the first spine surgery. For the principal } \\
\text { analysis, we considered the gross incidence }\end{array}$ \\
\hline Bias & 9 & $\begin{array}{l}\text { To avoid selection bias: "precise and exhaustive definition of SSI. Distinction between deep and superficial SSI } \\
\text { To avoid confounding bias: Multivariate analysis was used to identify independent risk factors of SSI }\end{array}$ \\
\hline Study size & 10 & Non-comparative study. The size of the cohort did not have previously calculated \\
\hline $\begin{array}{l}\text { Quantitative } \\
\text { variables }\end{array}$ & 11 & $\begin{array}{l}\text { Explain how quantitative variables were handled in the analyses. If applicable, describe which groupings were chosen and why } \\
\text { Methods (Page } 6 \text { Line 17): "Continuous data are described with mean } \pm \text { SD or median (25-75\% quartile)" } \\
\text { Methods (Page } 7 \text { Line 1): "Student } t \text { test or Mann-Whitney-Wilcoxon test was used for continuous variables" }\end{array}$ \\
\hline Statistical methods & 12 & $\begin{array}{l}\text { (a) Describe all statistical methods, including those used to control for confounding: continuous data are described with } \\
\text { mean } \pm \text { SD or median ( } 25-75 \% \text { quartile). Categorical data are described with number (percentage). } \\
\text { Incidence of SSI: gross incidence } \\
\text { Sensitivity analysis: incidence rate by survival using the Kaplan-Meier method. } \\
\text { SSI-free survival as the time from surgery to the occurrence of SSI } \\
\text { Cumulative survival as the time from the surgery to the occurrence of death } \\
\text { The starting point as the first surgery and the endpoint as the occurrence of SSI or the last follow-up } \\
\text { Data were censured for patients who were lost to follow-up or died. We defined the starting point as the first surgery and the } \\
\text { endpoint as the occurrence of death. Data were censured for patients who were lost to follow-up } \\
\text { Risk factors of SSI } \\
\text { Univariate analysis was used to assess the association of potential risk factors and SSI } \\
\text { Student } t \text { test or Mann-Whitney-Wilcoxon test was used for continuous variables and chi-square test or Fisher exact test for } \\
\text { categorical variables } \\
\text { Multivariate analysis (to control confounding bias): was used to identify independent risk factors of SSI. All variables } \\
\text { associated with SSI on univariate analysis ( } p<0.2) \text { were included in the logistic multiple regression analysis. The selection of } \\
\text { variables involved a stepwise method with a backward direction. The final model was checked for goodness of fit with the } \\
\text { Hosmer-Lemeshow test. As well, the discrimination of the final model was evaluated } \\
\text { Fisher test: Comparison of clinical outcomes (VAS score and SF-36) involved the non-parametric } \\
\text { (c) Explain how missing data were addressed: per protocol analysis } \\
\text { (d) Cohort study-if applicable, explain how loss to follow-up was addressed } \\
\text { Methods (Page } 6 \text { Line } 22 \text { ): "Data were censured for patients who were lost to follow-up or died" } \\
\text { (e) Describe any sensitivity analyses } \\
\text { Methods (Page } 6 \text { Line } 19 \text { ): For sensitivity analysis, we calculated the incidence rate by survival using the Kaplan-Meier } \\
\text { method }\end{array}$ \\
\hline
\end{tabular}


Table 5 continued

\begin{tabular}{|c|c|c|}
\hline Item & $\begin{array}{l}\text { Item } \\
\text { number }\end{array}$ & Recommendation \\
\hline \multicolumn{3}{|l|}{ Results } \\
\hline Participants & 13 & a) Report the numbers of individuals at each stage of the study \\
\hline Descriptive data & 14 & Confirmed eligible: 518 patients included 354 males $(68.3 \%)$. \\
\hline Outcome data & 15 & Included in the study: 518 patients included 354 males (68.3\%) completing followup and analyzed: At 1,3 and 12 months, we \\
\hline Outcome data & 16 & clinically assessed $478(92.2 \%), 476(91.8 \%)$ and 372 patients (72\%), respectively \\
\hline Main results & 17 & b) Give reasons for non-participation at each stage \\
\hline \multirow{16}{*}{ Other analyses } & & During the hospitalization: Results (Page 6 Line 10$)$ : "Five patients died during hospitalization $(0.01 \%)$ " \\
\hline & & At 3 months: Results (Page 8 Line 20): “At 3 months, 2 more patients died" \\
\hline & & At 12 months: Results (Page 8 Line 22): At 12 months, 2 more patients died, \\
\hline & & $\begin{array}{l}\text { (a) Give characteristics of study participants (e.g. demographic, clinical, social) and information on exposures and potential } \\
\text { confounders: }\end{array}$ \\
\hline & & Cf. the both paragraphs "Surgical procedure" (Tables 2,3) and "characteristics of the study sample" (Tables 2, 3) \\
\hline & & (b) Indicate the number of participants with missing data for each variable of interest \\
\hline & & $\begin{array}{l}\text { Results (Page } 8 \text { Line 13): "At 1, } 3 \text { and } 12 \text { months, we clinically assessed } 478(92.2 \%), 476(91.8 \%) \text { and } 372 \text { patients (72\%), } \\
\text { respectively" }\end{array}$ \\
\hline & & (c) Cohort study—summarize follow-up time (e.g. average and total amount): 12 months \\
\hline & & Cohort study-report numbers of outcome events or summary measures over time \\
\hline & & $\begin{array}{l}\text { Results (Page } 8 \text { Line } 22) \text { : "At } 12 \text { months, } 2 \text { more patients died, and the number of cases of SSI increased by } 3 \text { (25 SSI), with a } \\
\text { gross incidence rate of } 4.8 \% \text { (95\% CI [3.2-7.4\%])" }\end{array}$ \\
\hline & & $\begin{array}{l}\text { (a) Give unadjusted estimates and, if applicable, confounder-adjusted estimates and their precision (e.g. 95\% confidence } \\
\text { interval). Make clear which confounders were adjusted for }\end{array}$ \\
\hline & & and why they were included \\
\hline & & $\begin{array}{l}\text { Results (Page } 10 \text { Line 2): "Age, BMI, number of operated vertebrae and intraoperative blood loss were associated with SSI on } \\
\text { univariate analysis }(\text { all } p<0.05 \text { ). As well, the presence of diabetes, surgical duration }>3 \mathrm{~h} \text {, posterior surgical approach, } \\
\text { neurologic decompression, intraoperative blood transfusion, presence of bladder catheter and elevated NNIS score were } \\
\text { associated with SSI (all } p<0.05 \text { ). On multivariate analysis, only age, presence of diabetes and surgical duration }>3 \mathrm{~h} \text { were } \\
\text { predictors of SSI (all } p<0.05 \text { ) (Table 4)" }\end{array}$ \\
\hline & & (b) Report category boundaries when continuous variables were categorized \\
\hline & & No continuous variables were categorized \\
\hline & & Cf. results part \\
\hline \multicolumn{3}{|l|}{ Discussion } \\
\hline Key results & 18 & Summarize key results with reference to study objectives \\
\hline Limitations & 19 & \multirow{3}{*}{$\begin{array}{l}\text { Discussion (Page } 10 \text { Line } 11) \text { : "From a cohort of } 518 \text { patients, at } 12 \text { months after surgery for spinal injury, } 25 \text { showed SSI, for } \\
\text { a gross incidence rate of } 4.8 \%(95 \% \text { CI }[3.2-7.4 \%]) ; 16 \text { had acute SSI (<1-month duration). On multivariate analysis, age, } \\
\text { presence of diabetes and surgical duration }>3 \mathrm{~h} \text { were independent risk factors of SSI. These results are comparable with } \\
\text { those in the literature }[3,5,7] \text { " }\end{array}$} \\
\hline Interpretation & 20 & \\
\hline \multirow[t]{8}{*}{ Generalizability } & 21 & \\
\hline & & Discuss limitations of the study, taking into account sources of potential bias or imprecision \\
\hline & & Discuss both direction and magnitude of any potential bias \\
\hline & & $\begin{array}{l}\text { Discussion (Page } 12 \text { line } 3 \text { to 17): "The present study has some limitations (...) A larger cohort would be more adequate in a } \\
\text { context of a low rate of events" }\end{array}$ \\
\hline & & $\begin{array}{l}\text { Give a cautious overall interpretation of results considering objectives, limitations, multiplicity of analyses, results from } \\
\text { similar studies, and other relevant evidence }\end{array}$ \\
\hline & & $\begin{array}{l}\text { Discussion (Page } 12 \text { line } 3 \text { to 17): "The present study has some limitations (...) A larger cohort would be more adequate in a } \\
\text { context of a low rate of events" }\end{array}$ \\
\hline & & Discuss the generalizability (external validity) of the study results \\
\hline & & $\begin{array}{l}\text { Discussion (Page } 12 \text { Line 20): "More specific studies of the level of injury or kind of procedure would clearly establish risk } \\
\text { factors for SSI and improve the management of spinal injury needing surgery for stabilization [34, 35]" }\end{array}$ \\
\hline \multirow[t]{2}{*}{$\begin{array}{l}\text { Other information } \\
\text { funding }\end{array}$} & 22 & $\begin{array}{l}\text { Give the source of funding and the role of the funders for the present study and, if applicable, for the original study on which } \\
\text { the present article is based }\end{array}$ \\
\hline & & No funds. No conflict of interest \\
\hline
\end{tabular}

\section{References}

1. Liu P, Yao Y, Liu M, Fan W, Chao R, Wang Z et al (2012) Spinal trauma in mainland China from 2001 to 2007: an epidemiological study based on a nationwide database. Spine 37(15):1310-1315

2. Jarvis WR (1996) Selected aspects of the socioeconomic impact of nosocomial infections: morbidity, mortality, cost, and prevention. Infect Control Hosp Epidemiol Off J Soc Hosp Epidemiol Am 17(8):552-557

3. Blam OG, Vaccaro AR, Vanichkachorn JS, Albert TJ, Hilibrand AS, Minnich JM et al (2003) Risk factors for surgical site infection in the patient with spinal injury. Spine 28(13):1475-1480

4. Smith JS, Shaffrey CI, Sansur CA, Berven SH, Fu K-MG, Broadstone PA et al (2011) Rates of infection after spine surgery 
based on 108,419 procedures: a report from the Scoliosis Research Society Morbidity and Mortality Committee. Spine 36(7):556-563

5. Pull ter Gunne AF, Mohamed AS, Skolasky RL, van Laarhoven CJHM, Cohen DB (2010) The presentation, incidence, etiology, and treatment of surgical site infections after spinal surgery. Spine 35(13):1323-1328

6. Simchen E, Stein H, Sacks TG, Shapiro M, Michel J (1984) Multivariate analysis of determinants of postoperative wound infection in orthopaedic patients. J Hosp Infect 5(2):137-146

7. Rechtine GR, Bono PL, Cahill D, Bolesta MJ, Chrin AM (2001) Postoperative wound infection after instrumentation of thoracic and lumbar fractures. J Orthop Trauma 15(8):566-569

8. Mok JM, Guillaume TJ, Talu U, Berven SH, Deviren V, Kroeber $M$ et al (2009) Clinical outcome of deep wound infection after instrumented posterior spinal fusion: a matched cohort analysis. Spine 34(6):578-583

9. Lonjon G, Dauzac C, Fourniols E, Guigui P, Bonnomet F, Bonnevialle P et al (2012) Early surgical site infections in adult spinal trauma: a prospective, multicentre study of infection rates and risk factors. Orthop Traumatol Surg Res OTSR 98(7):788-794

10. Von Elm E, Altman DG, Egger M, Pocock SJ, Gøtzsche PC, Vandenbroucke JP et al (2007) The strengthening the reporting of observational studies in epidemiology (STROBE) statement: guidelines for reporting observational studies. Lancet 370(9596):1453-1457

11. Mangram AJ, Horan TC, Pearson ML, Silver LC, Jarvis WR (1999) Guideline for Prevention of Surgical Site Infection, 1999. Centers for Disease Control and Prevention (CDC) Hospital Infection Control Practices Advisory Committee. Am J Infect Control 27(2):97-132 (quiz 133-134; discussion 96)

12. Mangram AJ (2001) A brief overview of the 1999 CDC Guideline for the Prevention of Surgical Site Infection. Centers for Disease Control and Prevention. J Chemother Florence Italy 1(1):35-39

13. Bachy M, Bouyer B, Vialle R (2012) Infections after spinal correction and fusion for spinal deformities in childhood and adolescence. Int Orthop 36(2):465-469

14. Wimmer C, Gluch H (1996) Management of postoperative wound infection in posterior spinal fusion with instrumentation. J Spinal Disord 9(6):505-508

15. Fang X-T, Wood KB (2013) Management of postoperative instrumented spinal wound infection. Chin Med J (Engl) 126(20):3817-3821

16. Yim GW, Kim SW, Nam EJ, Kim S, Kim YT (2013) Learning curve analysis of robot-assisted radical hysterectomy for cervical cancer: initial experience at a single institution. J Gynecol Oncol 24(4):303-312

17. Jubert P, Lonjon G, Garreau de Loubresse C, Bone and Joint Trauma Study Group GETRAUM (2013) Complications of upper cervical spine trauma in elderly subjects. A systematic review of the literature. Orthop Traumatol Surg Res OTSR 99(6 Suppl):S301-S312

18. Deyo RA, Ciol MA, Cherkin DC, Loeser JD, Bigos SJ (1993) Lumbar spinal fusion. A cohort study of complications, reoperations, and resource use in the Medicare population. Spine. 18(11):1463-1470

19. Malik SA, Murphy M, Connolly P, O’Byrne J (2008) Evaluation of morbidity, mortality and outcome following cervical spine injuries in elderly patients. Eur Spine J. 17(4):585-591
20. Yoshihara H, Yoneoka D (2013) Trends in the Utilization of Blood Transfusions in Spinal Fusion in the United States From 2000 to 2009. Spine

21. Carreon LY, Puno RM, Dimar JR 2nd, Glassman SD, Johnson JR (2003) Perioperative complications of posterior lumbar decompression and arthrodesis in older adults. J Bone Joint Surg Am 85-A(11):2089-2092

22. Chuah LL, Papamargaritis D, Pillai D, Krishnamoorthy A, le Roux CW (2013) Morbidity and mortality of diabetes with surgery. Nutr Hosp 28(Suppl 2):47-52

23. Li G-Q, Guo F-F, Ou Y, Dong G-W, Zhou W (2013) Epidemiology and outcomes of surgical site infections following orthopedic surgery. Am J Infect Control

24. Kim BD, Hsu WK, De Oliveira GS Jr, Saha S, Kim JY (2013) Operative duration as an independent risk factor for postoperative complications in single-level lumbar fusion: an analysis of 4,588 surgical cases. Spine

25. Veeravagu A, Patil CG, Lad SP, Boakye M (2009) Risk factors for postoperative spinal wound infections after spinal decompression and fusion surgeries. Spine 34(17):1869-1872

26. Xing D, Ma J-X, Ma X-L, Song D-H, Wang J, Chen $Y$ et al (2013) A methodological, systematic review of evidence-based independent risk factors for surgical site infections after spinal surgery. Eur Spine J 22(3):605-615

27. Bracken MB, Shepard MJ, Collins WF, Holford TR, Young W, Baskin DS et al (1990) A randomized, controlled trial of methylprednisolone or naloxone in the treatment of acute spinal-cord injury. Results of the second national acute spinal cord injury study. N Engl J Med 322(20):1405-1411

28. Bracken MB, Shepard MJ, Holford TR, Leo-Summers L, Aldrich EF, Fazl M et al (1997) Administration of methylprednisolone for 24 or 48 hours or tirilazad mesylate for 48 hours in the treatment of acute spinal cord injury. Results of the Third National Acute Spinal Cord Injury Randomized Controlled Trial. National Acute Spinal Cord Injury Study. JAMA J Am Med Assoc. 277(20):1597-1604

29. Kuo C-H, Wang S-T, Yu W-K, Chang M-C, Liu C-L, Chen T-H (2004) Postoperative spinal deep wound infection: a six-year review of 3230 selective procedures. J Chin Med Assoc JCMA 67(8):398-402

30. Leonard HAC, Liddle AD, Burke O, Murray DW, Pandit H (2013) Single- or two-stage revision for infected total hip arthroplasty? A systematic review of the literature. Clin Orthop

31. Petilon JM, Glassman SD, Dimar JR, Carreon LY (2012) Clinical outcomes after lumbar fusion complicated by deep wound infection: a case-control study. Spine 37(16):1370-1374

32. Weiss LE, Vaccaro AR, Scuderi G, McGuire M, Garfin SR (1997) Pseudarthrosis after postoperative wound infection in the lumbar spine. J Spinal Disord 10(6):482-487

33. Uçkay I, Dinh A, Vauthey L, Asseray N, Passuti N, Rottman M et al (2010) Spondylodiscitis due to Propionibacterium acnes: report of twenty-nine cases and a review of the literature. Clin Microbiol Infect 16(4):353-358

34. Vitale MG, Riedel MD, Glotzbecker MP, Matsumoto H, Roye DP, Akbarnia BA et al (2013) Building consensus: development of a Best Practice Guideline (BPG) for surgical site infection (SSI) prevention in high-risk pediatric spine surgery. J Pediatr Orthop 33(5):471-478

35. Masgala A, Chronopoulos E, Nikolopoulos G, Sourlas J, Lallos S, Brilakis E et al (2012) Risk factors affecting the incidence of infection after orthopaedic surgery: the role of chemoprophylaxis. Cent Eur J Public Health 20(4):252-256 